Published as Tsou, J. Y. (2010). Putnam's Account of Apriority and Scientific Change: Its Historical and Contemporary Interest. Synthese, 176(3): 429-445.

\title{
Putnam's Account of Apriority and Scientific Change: Its Historical and Contemporary Interest
}

\author{
Jonathan Y. Tsou
}

\begin{abstract}
:
In the 1960s and 1970s, Hilary Putnam articulated a notion of relativized apriority that was motivated to address the problem of scientific change. This paper examines Putnam's account in its historical context and in relation to contemporary views. I begin by locating Putnam's analysis in the historical context of Quine's rejection of apriority, presenting Putnam as a sympathetic commentator on Quine. Subsequently, I explicate Putnam's positive account of apriority, focusing on his analysis of the history of physics and geometry. In the remainder of the paper, I explore connections between Putnam's account of relativized a priori principles and contemporary views. In particular, I situate Putnam's account in relation to analyses advanced by Michael Friedman, David Stump, and William Wimsatt. From this comparison, I address issues concerning whether $a$ priori scientific principles are appropriately characterized as "constitutive" or "entrenched". I argue that these two features need to be clearly distinguished, and that only the constitutive function is essential to apriority. By way of conclusion, I explore the relationship between the constitutive function a priori principles and entrenchment.
\end{abstract}




\section{Introduction}

In a series of papers in the 1960s and 1970s, Hilary Putnam (1962b, 1962a, 1976, 1979a) articulated an account of apriority that was motivated to address the problem of scientific change. Specifically, Putnam's analysis aimed to explain the special epistemological status that particular parts of scientific knowledge possess (or once possessed), while accommodating the putative occurrence of 'scientific revolutions'. In addressing this issue, Putnam argues that in the context of a body of physical knowledge, there are certain statements (e.g., ' $f=m a$ ', ' $e=1 / 2 m v^{2}$, the laws of Euclidean geometry) - what Putnam calls "framework principles" - that possess a privileged status. According to Putnam, these principles have an a priori or necessary status relative to a particular body of knowledge (e.g., $18^{\text {th }}$ century physics).

This paper examines Putnam's analysis of analyticity and apriority, both in its historical context and in relation to contemporary views. The paper proceeds as follows. In the first section, I locate Putnam's account in the historical context of Quine's (1951) criticism of analyticity, and present his account of apriority as a response to Quine. Subsequently, I explicate the main features of Putnam's positive account of apriority, focusing on his analysis of the history of physics and geometry. In the second half of the paper, I explore connections between Putnam's account of apriority and contemporary views. In particular, I situate Putnam's analysis in relation to recent analyses by Michael Friedman, David Stump, and William Wimsatt. From this comparison, I explore and address some issues concerning whether a priori scientific principles are appropriately characterized as "constitutive" (in a Reichenbachian sense) or "entrenched" (in a Quinean 
sense). I argue that these two features need to be clearly distinguished, and that only the former represents an essential feature of a priori scientific principles.

\section{Putnam as a Commentator on Quine}

Putnam's account of analyticity and apriority is formulated primarily in response to Quine's (1951) analysis in “Two Dogmas of Empiricism” (cf. Ebbs, 1997, ch. 6). In

“Two Dogmas Revisited”, Putnam (1976) reconstructs one of Quine's arguments against analyticity as a significant and cogent argument against the existence of a priori truths, i.e., statements that are true in all possible worlds or "immune from revision". In a wellknown passage from “Two Dogmas”, Quine writes:

The totality of our so-called knowledge or beliefs . . is a man made fabric which impinges on experience only along the edges . . . total science is like a field of force whose boundary conditions are experience. . . . But the total field is so underdetermined by its boundary conditions, experience, that there is much latitude of choice as to what statements to reëvaluate in the light of any single contrary experience. ... If this view is right, it is misleading to speak of the empirical content of an individual statement ... Furthermore, it becomes folly to seek a boundary between synthetic statements, which hold contingently on experience, and analytic statements, which hold come what may. Any statement can be held true come what may if we make drastic enough adjustments elsewhere in the system. Even a statement very close to the periphery can be held true in the face of recalcitrant experience by pleading hallucination or by amending certain statements of the kind called logical laws. Conversely, by the 
same token, no statement is immune to revision. Revision of even the logical law of the excluded middle has been proposed as a means of simplifying quantum mechanics; and what difference is there in principle between such a shift and the shift whereby Kepler superseded Ptolemy, or Einstein Newton, or Darwin Aristotle? (Quine, 1951, pp. 42-3, emphasis added)

Here, Quine articulates his holistic version of empiricism as an alternative to "dogmatic empiricism". As indicated by the last sentence of this passage, Quine believes that reflection on the history of science and scientific practices presents reasons for doubting the existence of unrevisable statements. ${ }^{1}$

Putnam reconceives Quine's argument as a "historical argument" against apriority. Specifically, Putnam (1976) emphasizes three points in the passage just cited (pp. 90-1). First, Quine's reference to the history of science is meant to highlight the fact that scientific principles that were once thought to be true for all times were eventually abandoned or revised. This is, arguably, Quine's strongest argument against apriority, and it can be understood as a pessimistic meta-induction against the existence of unrevisable truths. Implicit in Quine's argument is the assumption that there is no better standard for the epistemologist to adopt than the standards adopted by practicing scientists. As such, Quine recommends fallibilism with respect to truth. Second, in referring to non-standard logics and quantum mechanics, Quine suggests that fallibilism should to extend to logical laws. As Putnam puts it:

\footnotetext{
${ }^{1}$ Another perspective on this aspect of Quine's argument is that Quine presents an argument against the existence of "necessary truths", as opposed to "contingent truths". Since "revisability" is the issue that Putnam identifies as crucial, I think that contingency is what Putnam regards as correct in Quine's analysis. On this reading, Quine's argument can be viewed as an attack on the distinction between necessary and contingent truths, and Quine's position is that all statements should be regarded as having a contingent status.
} 
[Quine] is saying that proposals to use non-standard logics in quantum mechanics cannot be ruled out by any legitimate principle of scientific method. He is saying that the fallibilism which Peirce recognized as contributing essentially to the success of modern science extends also to the laws of logic. He is not just making a sociological remark to the effect that some scientists ... are willing to consider revision of logical laws ... He clearly thinks that it is right, fitting, and proper that they should be willing to allow such a possibility.... If this is right, then the laws of logic are not principles that a rational man is forbidden to revise. They are not clear and distinct ideas. They are not a priori truths. (Putnam, 1976, pp. 90-1, emphasis added)

Here, Putnam emphasizes that Quine's argument against apriority works by placing beliefs before the standards of actual scientific practices. On this reading, Quine is arguing that the notion of a priori truth is simply inconsistent with the fallibilist attitude characteristic of science. Third, Quine maintains that the proposal to use non-standard logic in quantum mechanics is not fundamentally different from the proposal to use nonEuclidean geometry in the theory of space-time. Taken together, Putnam understands Quine's argument to have shown that the history of science has no room for the notion of a priori truth as unrevisable truth.

The lesson to be drawn from Quine's “historical argument”, Putnam (1976) contends, is that "some statements can only be overthrown by rival theory; but there is no such thing as an absolutely unrevisable statement” (p. 94, emphasis in original). Conformably, Putnam rejects an absolutist notion of apriority. Putnam writes: 
The concept of an a priori truth that I reject is historically best represented by Descartes' notion of a clear and distinct idea. Descartes' clear and distinct ideas were in a certain sense self-certifying truths. They bore their validity on their face. Not only could it never be rational to give up such a truth; it could never be rational to doubt one. (Putnam, 1979b, p. viii)

Putnam believes that this traditional notion of a priori truth, i.e., necessary truths that no rational person would deny (e.g., ' $1+1=2$ ' or 'The sum of the interior angles of any triangle is 180 degrees') has been decisively undermined by Quine's analysis. Putnam goes as far as suggesting that Quine's argument is of great philosophical significance, and that Quine should be credited with disabusing philosophers of this traditional notion of apriority. Putnam writes:

Quine ... considers ... the notion of analytic truth as one that is confirmed no matter what. I . . contend that this is the traditional notion of apriority, or rather, one of the traditional notions of apriority. This notion, or variants thereof, has played a central role in all of philosophy since the ancients, and in all the different branches of philosophy. Moreover, I think that Quine's attack on this notion was correct. ... If I am right, Quine is a philosopher of historic importance ... because he was the first philosopher of the top rank ... to reject the notion of apriority. . [I]f I am wrong and there is such a thing as a priori truth, then I am doubtless overestimating Quine's importance in the history of philosophy. There are some philosophers in the history of philosophy whose importance does not very much depend on their being right. But Quine's importance does, I think, depend to a large measure upon his being right in one central claim, a claim which 
he expressed by saying that there is no sensible distinction between analytic and synthetic truths but which he should have expressed by saying that there is no sensible distinction between a priori and a posteriori truths. (Putnam, 1976, pp. $87-8$, emphasis in original)

Leaving aside issues regarding Putnam's assessment of Quine's importance, I want to highlight Putnam's endorsement of Quine's rejection of apriority as the appropriate background for understanding Putnam's positive account of analyticity and apriority.

\section{The Analytic and the Synthetic}

Although the starting point for Putnam's analysis is a Quinean rejection of apriority, Putnam (contra-Quine) does not reject the analytic-synthetic distinction - or the a prioria posteriori - distinction entirely. Putnam's position can be understood as rejecting an analytic-synthetic dichotomy, but affirming an analytic-synthetic distinction (cf. Putnam, 1994a, p. 249). In the following section, I outline Putnam's positive account of the analytic-synthetic distinction, focusing on his analysis of the history of physics and geometry. Although I follow Putnam's (1962b) terminology in presenting his account as an account of the analytic-synthetic distinction, it should be recognized — given Putnam's understanding of Quine - that the a priori-a posteriori distinction is, arguably, the main target of his analysis.

In "The Analytic and the Synthetic", Putnam (1962b) aims to articulate a positive account of the analytic-synthetic distinction "both inside and outside of physical theory" (p. 33). Putnam is concerned with an analytic-synthetic distinction in natural languages 
and, following Quine, he maintains that the analytic-synthetic distinction is a distinction of degree, not of kind. Putnam writes:

$[\mathrm{O}] \mathrm{n}$ the whole my story will resemble Quine's. That is to say, I believe that we have a conceptual system with centralities and priorities. I think that the statements in that conceptual system - except for the trivial examples of analyticity, e.g., 'All bachelors are unmarried', 'All vixens are foxes' - fall on a continuum, a multi-dimensional continuum. More or less stipulation enters; more or less systematic import. But any one of these principles might be given up ... With Quine, I should like to stress the monolithic character of our conceptual system, the idea of our conceptual system as a massive alliance of beliefs which face the tribunal of experience collectively and not individually, the idea that 'when trouble strikes' revisions can with a very few exceptions, come anywhere. (Putnam, 1962b, p. 40, emphasis added)

Here, Putnam characterizes the general feature of "analytic" statements as statements that involve a greater degree of "stipulation". ${ }^{2}$ Moreover, by speaking of analytic statements in terms of "centralities" and "priorities", his account purports to distinguish these statements in terms of the epistemic reasons that we have for believing them. Finally, Putnam's account distinguishes between "trivial" analytic statements such as 'all bachelors are unmarried', and analytic statements in science (see Putnam, 1962b, pp. 5069; Ebbs, 1997, pp. 163-4). The focus of this paper will be on the latter.

Putnam articulates his account of analyticity with reference to cases of theory change in science. For instance, consider the definition of kinetic energy before and after

\footnotetext{
${ }^{2}$ Although Putnam characterizes analytic principles in science - on a general level - as "stipulated definitions", he opposes conventionalist perspectives on these principles (e.g., see Putnam 1975, ch. 9).
} 
Einstein. In pre-relativistic physics, the statement ' $e=1 / 2 m v^{2}$ ' was the definition of kinetic energy in the sense that 'kinetic energy' was regarded as a short-hand abbreviation for 'one-half mass times velocity squared'. However, in the context of the special theory of relativity, Einstein required that physical laws (e.g., the law of gravitation) be Lorentz-invariant, i.e., physical laws must remain unchanged by a Lorentz transformation. In accordance with this principle, Einstein replaced the definition of 'kinetic energy' with a more complicated law (viz., ' $e=m c^{2}+1 / 2 m v^{2}$...' when expanded as a power-series). For Putnam, this case of theory change highlights the peculiar status that ' $e=1 / 2 m v^{2}$ ' possessed in the historical context of pre-relativistic physics. In this context, ' $e=1 / 2 m v^{2}$ ' was regarded as immune from revision in the precise sense that it served as a necessary presupposition for framing empirical experiments. Putnam writes: The principle ' $e=1 / 2 m v^{2}$ ' may have been introduced $\ldots$ by stipulation; the Newtonian law of gravitation may have been introduced on the basis of induction from the behavior of the known satellite system and the solar system (as Newton claimed); but in subsequent developments these two famous formulas were to figure on a par. Both were used in innumerable physical experiments until they were challenged by Einstein, without ever being regarded as themselves subject to test in the particular experiment. If a physicist makes a calculation and gets an empirically wrong answer, he does not suspect that the mathematical principles used in the calculation may have been wrong ... nor does he suspect that the law ' $f=m a$ ' may be wrong. Similarly, he did not frequently suspect before Einstein that the law ' $e=1 / 2 m v^{2}$ ' might be wrong or that the Newtonian gravitational law might be wrong. ... These statements, then, have a kind of preferred status. They 
can be overthrown only if someone incorporates principles incompatible with those statements in a successful conceptual system. (Putnam, 1962b, pp. 45-46, emphasis added)

For Putnam, the status of principles such as ' $e=1 / 2 m v^{2}$ ' are analytic in the sense that in the context of pre-relativistic physics no single experiment could ever overthrow such principles; these principles need to be presupposed in order to frame empirically meaningful experiments. In this precise sense, the kinetic definition of energy and Newton's law of gravitation possessed a necessary or quasi-necessary status in the context of pre-relativistic physics.

Putnam reaches similar conclusions on the status of Euclidean geometry. Putnam (1962b) states that before the work of Riemann, Lobachevski, and others in the $19^{\text {th }}$ century - that would subsequently lead to the overthrow of Euclidean geometry - "the principles of Euclidean geometry were as close to analytic as any nonanalytic statement ever gets", in the sense that "no experiment that one could describe could possibly overthrow them" (p. 48). However, after the development of the special theory of relativity and non-Euclidean geometry, scientists were given reasons to revise Euclidean geometry.

Putnam summarizes his analysis of the history of physics and geometry by calling principles such as ' $e=1 / 2 m v^{2}$ ', ' $f=m a$ ', and the principles of Euclidean geometry 'framework principles'. According to Putnam:

'[F]ramework principles' ... have the characteristic of being so central that they are employed as auxiliaries to make predictions in an overwhelming number of experiments, without themselves being jeopardized by any possible experimental 
results. This is the classical role of the laws of logic; but it is equally the role of certain physical principles, e.g., ' $f=m a$,' . . the laws of Euclidean geometry, and the law ' $e=1 / 2 m v^{2}$ ', at the time when those laws were still accepted. (Putnam, 1962b, pp. 48-9, emphasis added)

As indicated here, framework principles, for Putnam, possess three key characteristics: (1) they serve as necessary presuppositions for various experiments, (2) they are regarded as a priori, and are themselves immune from physical testing, and (3) their revision or abandonment often requires the development of an entirely new conceptual scheme.

\section{Framework Principles and the Contextual A Priori}

Putnam affirms the existence of principles in science that have a relativized a priori status. Putnam writes:

My account does not deny - indeed it affirms - that there is a distinction between truths which are a priori relative to a particular body of knowledge and truths which are empirical relative to a particular body of knowledge. What it denies is that there are truths which are a priori relative to ... the context of 'all contexts'. The context of 'all contexts' is no context at all. (Putnam, 1979b, p. x) Elsewhere, Putnam (1962a, 1962b, 1976, 1978, 1994a) has characterized the status of these principles as "contextually a priori", "necessary relative to a body of knowledge", and "quasi-necessary relative to a conceptual scheme". However this distinction is presented, Putnam's approach to apriority is characterized by a rejection of absolute $a$ 
priori truths, and an affirmation of relativized a priori truths in science. Putnam has presented this "moderate Quinean" position as an account of contextual apriority: [My position] ... does not deny that there at least appear to be a priori truths, it does not deny that certain truths have a special status, it tries to explain why that is so.... The idea is that we can grant that certain truths ... have a special status, but that we don't have to concede that that status is good old-fashioned apriority. The status these truths and falsehoods have, as long as they have it, is contextual apriority: apriority relative to the body of knowledge.... What still seems to me to be right about this is the idea that there is such a status as contextual apriority, and the idea that contextual apriority has sometimes been mistaken for absolute apriority, i.e., for the status that a statement has if . . it could never be rational to revise it. (Putnam, 1978, p. 99, emphasis added)

In endorsing this deflationary account of apriority, Putnam's analysis bears similarity to some recent accounts of apriority defended by philosophers of science (e.g., Friedman, 2001; Stump 2002), a topic that I subsequently address. ${ }^{3}$

Putnam's analysis is somewhat confusing due to his idiosyncratic usage of terms such as "analytic", "a priori", and "necessary" (e.g., see Putnam, 1962a, 1962b, 1976, 1994a). For the sake of clarity and consistency, I will hereafter use "framework principles" to refer to what Putnam characterizes as scientific principles that possess a relativized a priori or necessary status. Putnam's retention of these older philosophical

\footnotetext{
${ }^{3}$ Putnam's account also bears similarity with the older formulation of theory change in physics proffered by Hans Reichenbach ([1920] 1965). Putnam studied physics and geometry with Reichenbach and, in conversation, Putnam has acknowledged that his account of apriority is "very similar" to Reichenbach's neo-Kantian treatment of apriority (cf. Putnam, 1994b, p. vii). Putnam has also indicated that when he wrote his analyses of apriority in the 1960s and 1970s, he had not yet read Reichenbach's 1920 book.
} 
terms, I think, stems from the fact that he wants to salvage and explicate what he regards as a real distinction in natural languages that has traditionally marked certain classes of statements as "a priori" or "analytic". That is, the statements that Putnam identifies as framework principles approach what have traditionally been given an "a priori" or “analytic" status. On this reading, Putnam's account should be regarded not only as clarifying the a priori-a posteriori (or analytic-synthetic) distinction in natural languages, but replacing these older formulations with a workable distinction.

Framework principles are given a special epistemological status in Putnam's account. As indicated above, these principles possess a necessary or a priori status relative to a conceptual scheme, as opposed to a contingent or a posteriori status. Retrospectively, Putnam (1994a) explains this distinction as follows:

[C]all a statement empirical relative to a body of knowledge B if possible observations ... would be known to disconfirm the statement ... Statements which belong to a body of knowledge but which are not empirical relative to that body of knowledge I called "necessary relative to the body of knowledge." . . The point of this new distinction was ... to emphasize that there are at any given time some accepted statements which cannot be overthrown merely by observations, but can only be overthrown by thinking of a whole body of alternative theory as well (p. 251, emphasis in original).

Putnam qualifies this distinction by stating that framework principles should properly be characterized as "quasi-necessary relative to conceptual scheme" given the abnormality of calling potentially false statements "necessary" or "a priori" (whether these statements are contextualized or not). 
Putnam stresses that his account of framework principles is not simply meant to identify principles that scientists are psychologically unwilling to give up. As Putnam (1994a) puts it:

I would . . . emphasize the nonpsychological character of the distinction by pointing out that the question is not a mere question of what some people can imagine or not imagine; it is a question of what, given a conceptual scheme, one knows how to falsify or at least disconfirm. Prior to Lobachevski, Riemann, and others, no one knew how to disconfirm Euclidean geometry, or even knew if anything could disconfirm it. (p. 251, emphasis added)

Putnam's account identifies a distinction between principles that cannot presently be disconfirmed by available methods and evidence, on the one hand, and principles that can be presently disconfirmed by observations. This feature of Putnam's account is meant to explain why it was rational for scientists (e.g., in the era of Newtonian mechanics) to regard framework principles (e.g., Euclidean geometry) as immune to revision. The rationality of this belief is explained by the fact that scientists did not possess the requisite theoretical background necessary to disconfirm those framework principles. For this reason, Putnam claims that - from a epistemological point of view - framework principles possess a "quasi-necessary" status.

\section{The Contemporary Relevance of Putnam's Analysis}

In the remainder of this paper, I examine Putnam's account of framework principles in relation to some contemporary accounts of analyticity and apriority in science.

Specifically, I compare Putnam's account to the accounts of Michael Friedman (1997; 
2001), David Stump (2003), and William Wimsatt (1987; forthcoming). The aim of this comparison is to further clarify the nature of Putnam's framework principles, and to examine some issues that are not directly addressed by his analysis. Specifically, I examine whether Quinean entrenchment is an essential feature of a priori principles in science, arguing - against Putnam and Wimsatt - that it is not.

Michael Friedman is the most well-known contemporary writer who has emphasized the importance of relativized a priori principles in science. In a number of works, Friedman $(1997,1999,2001)$ has argued that the history of physics demonstrates that relativized a priori principles have been central in the formulation of physical theories. ${ }^{4}$ On a general level, Putnam and Friedman's accounts of the relativized a priori are remarkably similar insofar as they both affirm the existence of a priori principles in science that are both revisable and relativized to a particular body of knowledge. On a more specific level, however, Friedman provides a more detailed and comprehensive account of the history of physics.

In his most developed account of apriority, Friedman (2001) argues that physical theory can be distinguished into three asymmetrically functioning parts (pp. 79-82):

(1) A mathematical part (mathematical/ geometrical principles) that includes basic mathematical theories that are employed to describe the spatio-temporal framework.

(2) A mechanical part (coordinating principles) that functions to set up a correspondence between the mathematical part [1] and empirical part [3].

\footnotetext{
${ }^{4}$ For a more comprehensive discussion of Friedman's (2001) conception of relativized a priori principles, see DiSalle (2002), Richardson (2002), and Lange (2004).
} 
(3) An empirical part (empirical/ physical principles) that uses the theories in the mathematical part [1] to formulate empirical laws [3] that describe concrete phenomena.

According to Friedman, in the context of any physical theory, both the mathematical principles and coordinating principles are relativized a priori in the sense that - taken together - they are constitutive of the empirical part. ${ }^{5}$ In Newonian mechanics, e.g., Euclidean geometry [1] and the Newtonian laws of motion [2] are relativized a priori insofar as they are constitutive of empirical laws such as the law of universal gravitation [3]. In special relativity, the geometry of Minkowski space-time [1] and the light principle [2] are relativized a priori insofar as they are constitutive of empirical laws such as Maxwell's equations for the electromagnetic field [3]. In general relativity, the theory of (semi-) Riemannian space-time manifolds [1] and the principle of equivalence [2] are relativized a priori insofar as they are constitutive of empirical laws such as Einstein's equations for the gravitational field [3].

The significance of mathematical and mechanical principles, for Friedman, is the constitutive function that they serve. Friedman (2001) writes: "What characterizes the distinguished elements of our theories is ... their special constitutive function: the function of making the precise mathematical formulation and empirical application of the theories in question first possible" (p. 40, emphasis in original). For Friedman, relativized a priori principles are required to raise the very possibility of objective (i.e.,

\footnotetext{
${ }^{5}$ While both the mathematical and mechanical parts, on Friedman's account, are relativized a priori, Friedman's (2001) picture suggests that the mathematical part is more fundamental (or, "more a priori") than the coordinating part insofar as the latter presuppose the former, e.g., ' $f=$ ma' could not have been formulated without the mathematics of the calculus (see Friedman, 2001, pp. 35-7). Friedman's tripartite manner of distinguishing physical theory is helpful for clarifying a way in which a priori principles can be differentiated with respect to "degrees of apriority". This rendering of Friedman's view, I think, is helpful for elaborating Putnam's "continuum" picture of apriority.
} 
intersubjective) empirical laws which can then be tested, e.g., Newton's description of the solar system in book 3 of Principia or Einstein's calculation of the advance of the perihelion of Mercury. In this manner, Friedman highlights a particular functional relationship of dependence between a priori and a posteriori principles in the context of any physical theory. In particular, Friedman maintains that relativized a posteriori principles of a theory presuppose, as necessary background assumptions, relativized $a$ priori principles. ${ }^{6}$

A curious difference between Putnam and Friedman's accounts is that Putnam formulates his analysis through Quinean insights, whereas Friedman formulates his account in explicit opposition to the sort of Quinean web-of-belief holism endorsed by Putnam. For instance, Friedman (2001) argues that the history of mathematical physics indicates that:

... entrenchment and resistance to revision are not appropriate distinguishing features [of scientific knowledge].... What characterizes the distinguished elements of our theories is ... their special constitutive function ... In this sense, the relativized and dynamical conception of the a priori ... appears to describe . . . conceptual revolutions far better than does Quinean holism (p. 40).

Friedman argues that Quine's holism obscures the functional relationship of dependence that obtains between different statements within a particular body of knowledge, viz., $a$ posteriori principles and the relativized a priori principles that are constitutive of them. This places Friedman in direct opposition to Putnam's characterization of analytic

\footnotetext{
${ }^{6}$ Friedman's formulation is, I believe, amenable to Putnam's (1994a) presentation of framework principles as being 'necessary relative to B' as opposed to 'empirical relative to B' (p. 251). What is not emphasized in Putnam's account, however, is the asymmetric functional relation of dependence that Friedman stresses between 'statements necessary in B' and 'statements empirical in B'.
} 
principles as "resistant to revision". Against the idea that relativized a priori are accurately characterized as entrenched or resistant to revision, Friedman points out that when Newton formulated his universal law of gravitation, the new calculus was itself controversial (i.e., since it lacked a consistent formulation). Similarly, when Einstein formulated the general theory of relativity, neither the Riemannian theory of manifolds nor the principle of equivalence were deeply entrenched principles (Friedman, 2001, pp. 39-40). This suggests that as a characteristic of a priori principles, "entrenchment" may be a characteristic that is independent from the precise constitutive role that Friedman attributes to these principles.

Drawing on Friedman's work, David Stump (2003) has articulated an account of conventions as "functionally a priori" ${ }^{7}$ Stump's analysis is helpful for clarifying the aforementioned issue of a priori principles as entrenched versus serving a constitutive role. Stump (2003) writes:

[S]ome elements of our physical theory have a unique epistemological status one must adopt these elements in order to begin empirical inquiry. They therefore function as an a priori part of our physical theory that is chosen for conceptual or pragmatic reasons, prior to any empirical testing. Though I am willing to concede to Quine that these conventions are ultimately empirical, the picture of knowledge is very different from ... Quinean holism in that categories of knowledge can be differentiated. While Quine admits that some elements of empirical theory are much less likely to be revised than others, he underestimates the asymmetric relation between the "hard core" and the "periphery". It is not just that the

\footnotetext{
${ }^{7}$ Although Stump argues that "conventions" have a functionally a priori status, he emphasizes that these conventions are ultimately chosen on the basis of empirical considerations (cf. Putnam, 1962a, pp. 239-42).
} 
periphery is more likely to be revised than the hard core, but rather that the statements of the periphery cannot even be stated, let alone tested, without the hard core functioning as an a priori in the Kantian sense as a necessary precondition (p. 1150, emphasis added). Like Friedman, Stump believes that Quine's holistic picture of theory change is misleading insofar as it obscures the constitutive role that a priori principles serve within a particular conceptual scheme. Although Quine grants that certain beliefs are located at the periphery of the "web" and more likely to be revised (e.g., beliefs about biology), while other beliefs (e.g., logical laws) are more central and less likely to be revised, Quine's web-of-belief conception of theory change does not appear to have the resources necessary to account for the constitutive function that Friedman and Stump have identified as the most important distinguishing feature of a priori principles. For Friedman and Stump, to characterize these principles as merely "entrenched" misses the point.

In two papers, William Wimsatt (1987, forthcoming) has proffered a naturalistic account of apriority in science. ${ }^{8}$ Like Putnam, Wimsatt adopts a broadly "Quinean" stance, characterizing "analytic" principles as being (1) "unfalsifiable", and (2) "polyfunctional". In stating that analytic statements are unfalsifiable, Wimsatt suggests that certain scientific principles are "highly resistant to revision" or "entrenched". Like

\footnotetext{
${ }^{8}$ Although Wimsatt presents his analysis as a way of understanding the analytic-synthetic distinction, in conversation he has said that his account is also applicable to the a priori-a posteriori distinction. Wimsatt's analysis is presented in the context of his theory of "generative entrenchment" (see Wimsatt, 2001). Generative entrenchment is a developmental-evolutionary model intended to model evolutionary processes in various domains (e.g., biology, science, and culture). For the purposes here, it is important to note that Wimsatt (1987) characterizes "analytic principles" in science as "generatively entrenched" structures, meaning that analytic principles play a role in generating other parts of scientific knowledge, and they are entrenched in the sense that they have become increasingly stable (or 'immune to revision') over a period of time.
} 
Quine and Putnam, Wimsatt maintains that this resistance is due to the high pragmatic cost involved with revising these statements (e.g., the law of non-contradiction) given their centrality in a system of knowledge. Thus, the basis for the "unfalsifiability" of analytic statements for Wimsatt is pragmatic. In calling analytic principles polyfunctional, Wimsatt suggests that these principles are applicable in a variety of domains and "portable" in the sense that they can be used in a wide variety of contexts, interpreted differently, and used in different forms to describe and predict things about diverse systems.

In articulating his account of analyticity, Wimsatt makes reference to Kuhn's (1970, pp. 182-3) discussion of “fundamental laws” in physics. Wimsatt endorses Kuhn's idea that ' $f=m a$ ' functions as an analytic statement insofar as it is a "general law schema" (rather than an empirical law) that functions to generate empirical propositions. That is, ' $f=m a$ ' functions as a "general guide" for translating and generating empirical laws in a variety of theoretical contexts. In this precise sense, Wimsatt maintains that ' $f=$ $m a$ ' possesses a "quasi-definitional” status. In explaining how such principles acquire such a status, Wimsatt writes:

The path from generative entrenchment to polyfunctionality to abstraction, to the resultant schematic character of such propositions, to their increased unfalsifiability and portability ... is the main path [through] which an [initially] empirical generalization acquires a quasi-definitional status. It may now be regarded as a truth in meaning, and in formalizations of the theory, it may be treated as an analytic proposition (Wimsatt, 1987, p. 12, emphasis added). 
Here, Wimsatt outlines a process whereby an initially empirical theory becomes transformed into a portable tool of analysis, which acquires a quasi-analytic status (also see Wimsatt, forthcoming; cf. Friedman, 2001, pp. 88-9). For the purposes here, I want to bring attention to Wimsatt's emphasis on the generative function of analytic or a priori principles. On Wimsatt's account, a priori principles are generative heuristics that can subsequently be applied in a variety of contexts.

Wimsatt's analysis of analyticity is particularly interesting for its discussion of "analytic" principles in the context of theories of biology. For instance, Wimsatt argues that Richard Lewontin's (1970) formulation of “Darwin's principles" serves as a good example of analytic principles insofar as these principles function schematically to provide a general framework for understanding evolution for various "units of selection". Lewontin (1970) presents these principles as three conditions that an evolutionary system must fulfill in order for change to occur (p. 1):

(1) Phenotypic variation: different individuals in a population have different morphologies, physiologies, and behaviors.

(2) Differential fitness: different phenotypes have different rates of survival and reproduction in different environments.

(3) Fitness is heritable: there is a correlation between parents and offspring in the contribution of each to future generations.

According to Wimsatt, the formulation of these principles as such is the result of a process of analysis, generalization, and abstraction, wherein an initially empirical theory (viz., Darwin's theory of natural selection) has been transformed into a portable tool of analysis that can be applied in a variety of contexts. For this reason, Wimsatt thinks that 
Darwin's principles have acquired a quasi-definitional status. As another example from biology, Wimsatt suggests that even diagrams, such as August Weissman's diagrams that were used to represent the continuity of the germ plasm and the causes of somatic differentiation can be regarded as having a quasi-analytic status insofar as these diagrams were subsequently applied to indicate corrections in both Weissman's and competing views.

\section{Apriority, Constitutive Principles, and Entrenchment}

In the following section, I want to briefly address some issues raised in the previous section. In particular, I examine the relationship between apriority, the constitutive function of scientific principles, and entrenchment. Like Putnam, all of the philosophers discussed above provide accounts of relativized a priori principles. Moreover, all of these writers have agreed with Putnam's idea that these principles possess a "necessary" or “quasi-necessary” status. Friedman and Stump's analyses elaborate this role more precisely in the idea that a priori principles serve a (neo-Kantian) constitutive function. Wimsatt's analysis suggests further that these principles can be regarded as generative heuristics that can subsequently be reapplied in various contexts. While Putnam and Wimsatt claim that a feature of a priori principles is their resistance to revision (or entrenchment), Friedman and Stump argue that that entrenchment is not an essential element of apriority.

Friedman and Stump's analyses of apriority suggest (contra-Putnam and Wimsatt) that Quine's notions of "entrenchment" and "resistance to revision" are inappropriate characteristics to attribute to a priori scientific principles. I think that 
Friedman and Stump are correct. As we have seen, Putnam argues that relativized $a$ priori principles are "highly resistant to revision" because - in a given historical context - there are no possible experiences that could falsify those principles (and this is a claim that Friedman and Stump would accept). However, this "quasi-necessary" characteristic of a priori scientific principles needs to be clearly distinguished from the high pragmatic cost that is associated with revising such principles (which I take to be the central idea in Quine's notion of entrenchment). This stance recognizes that the crucial constitutive methodological function that these principles serve needs to be separated from the issue of how willing scientists would be to give up or revise these principles (regardless of the rationality of such beliefs). On this picture, one would expect relativized a priori principles that have been highly successful, effective, and useful (e.g., the laws of logic, the principles of Euclidean geometry, ' $f=m a$ ', Darwin's principles of natural selection) to also be characterized by greater resistance to revision or entrenchment. Moreover, such successful a priori principles would be akin to the generative structures discussed by Wimsatt that have acquired a quasi-definitional status. For the purposes here, I want to emphasize that the constitutive function served by framework principles needs to be clearly separated from the issue of whether these principles are entrenched.

Furthermore, I would argue against the very usefulness of Quine's web-of-belief metaphor, which characterizes highly entrenched scientific principles, lying at the core of the web, as being fundamentally non-testable assumptions. Consider the example of Avogadro's number (i.e., the number of molecules in a mole of any substance: $6.022 \times$ $10^{23}$ ). In Quine-speak, Avogadro's number is a 'deeply entrenched' principle. On the other hand, it is quite clear - in contrast to Quine's web-of-belief picture - that 
Avogadro's number is highly susceptible to empirical testing. In fact, in the early twentieth century, Jean Perrin ([1913] 1923) identified thirteen independent methods by which Avogadro's number had been experimentally ascertained, e.g., Perrin's experimental work on Brownian motion, Rutherford's study of radioactivity, and Planck's work on blackbody radiation. ${ }^{9}$ What the case of Avogadro's number demonstrates, I think, is that Quine is mistaken to suggest that an essential feature of highly entrenched principles is their empirical untestability. Accordingly, I think that one ought to resist the temptation of translating the constitutive function of a priori principles into the language of Quine's web-of-belief view (cf. Stump, 2003).

These observations on entrenchment motivate an argument against conflating the constitutive function of a priori scientific principles with the entrenchment of such principles. According to the analysis given here, a central feature of a priori principles is the constitutive function that they serve: in the context of any given theory, these principles serve as necessary presuppositions for framing empirical experiments, and are not themselves testable. What is significant is that relativized a priori principles stand in an asymmetric relation to the a posteriori principles in the theory (with the latter presupposing the former). Accordingly, these principles are regarded as having a quasidefinitional status in a conceptual scheme, and in this precise sense, are "prior to experience". This constitutive feature of a priori principles, however, needs to be clearly separated from the issue of whether these principles are entrenched. While it stands to reason - as suggested by Wimsatt's analysis - that in order to acquire a definitional status

\footnotetext{
${ }^{9}$ For discussion of Perrin's analysis of Avogadro's number, see Nye (1972) and Salmon (1984, ch. 8). In his classic treatment, Wesley Salmon presents Perrin's work as an argument for the reality of atoms and molecules that utilizes a common-cause principle.
} 
such principles need first to be deeply entrenched, this is not always the case, e.g., as in the case of the calculus when Newton formulated his universal law of gravitation. What can be said is that entrenchment is one of the typical historical paths by which a scientific principle comes to acquire a quasi-definitional status. As such, entrenchment is not an essential feature of a priori principles, although it might be highly correlated with apriority.

\section{Conclusion}

In examining Putnam's account of apriority, and comparing his account to more recent accounts, my aim was to arrive at some substantive conclusions regarding the nature and role of a priori knowledge in science. One of the main issues addressed in this paper concerned the question of whether it is appropriate to characterize a priori principles as constitutive or entrenched. I argued that these two characteristics need to be carefully distinguished, and in light of Putnam and Wimsatt's shared view that a priori principles are 'resistant to revision', I argued that only the constitutive function represents an essential feature of a priori scientific principles.

By way of conclusion, let me briefly summarize what I regard to be the fundamental features of a priori scientific principles. First, in the context of any given theory, a priori principles are constitutive of the empirical parts of a theory, and can be understood as necessary assumptions for framing empirical experiments and laws. As suggested by Putnam and Friedman's analyses, different principles within a body of knowledge may possess different degrees of apriority, depending on the level of generality associated with the principles in question. Second, regardless of how such 
principles are introduced (e.g., by stipulation or as the result of abductive inference), $a$ priori principles possess a definitional or quasi-definitional status relative to a body of knowledge. That is, within a body of knowledge, these principles are regarded as definitions. Taken together, these two features constitute the precise sense in which $a$ priori principles are "prior to experience". As argued in the last section of this paper, these principles will often display the characteristics of being deeply entrenched or resistant to revision, but - as I argued - these are not essential features a priori principles. In fact, I would suggest that entrenchment and resistance to revision are derivative features of the two central features mentioned above. With respect to the deeply entrenched nature of some a priori principles (e.g., Euclidean geometry), this points to the fact that deeply entrenched principles often come to acquire a definitional status. Yet, it is clear that there are alternative paths by which scientific principles (e.g., nonEuclidean geometry) can come to possess such a definitional status. With respect to the resistance to revision or "unfalsifiability" that Putnam and Wimsatt attribute to a priori principles, this may stem from the fact that such principles play such a fundamental and central role within the context of a theory that there would be high pragmatic costs associated with revising such principles. As argued in this paper, however, it is an error to identify this entrenchment with what gives a priori scientific principles their special epistemological status. 


\section{References}

DiSalle, Robert: 2002, 'Reconsidering Kant, Friedman, Logical Positivism, and the Exact Sciences', Philosophy of Science 69, 191-211.

Ebbs, Gary: 1997, Rule-Following and Realism, Harvard University Press, Cambridge, MA.

Friedman, Michael: 1997, 'Philosophical Naturalism', Proceedings and Addresses of the American Philosophical Association 71, 7-21.

Friedman, Michael: 1999, Reconsidering Logical Positivism, Cambridge University Press, Cambridge.

Friedman, Michael: 2001, Dynamics of Reason, CSLI Publications, Stanford, CA.

Kuhn, Thomas S.: 1970, The Structure of Scientific Revolutions, $2^{\text {nd }}$ ed., University of Chicago Press, Chicago, IL.

Lange, Marc: 'Review Essay on Dynamics of Reason by Michael Friedman', Philosophy and Phenomenological Research, 68, 702-712.

Lewontin, Richard C.: 1970, 'The Units of Selection', Annual Review of Ecology and Systematics 1, 1-18.

Nye, Mary Jo: 1972, Molecular Reality, Macdonald, London.

Perrin, Jean: [1913]/ 1923, Atoms, trans. D. L. Ammick. Van Nostrand, New York.

Putnam, Hilary: 1962a, 'It Ain’t Necessarily So', reprinted in Putnam (1979b), pp. 237-249.

Putnam, Hilary: 1962b, 'The Analytic and the Synthetic', reprinted in Putnam (1975), pp. 33-69.

Putnam, Hilary: 1975, Mind, Language and Reality: Philosophical Papers, vol. 2, Cambridge University Press, Cambridge, pp. 33-69.

Putnam, Hilary: 1976, “'Two Dogmas' Revisited', reprinted in Putnam (1983), pp. 87-97.

Putnam, Hilary: 1978, 'There Is At Least One A Priori Truth', reprinted in Putnam (1983), pp. 98-114.

Putnam, Hilary: 1979a, 'Analyticity and Apriority: Beyond Wittgenstein and Quine', reprinted in Putnam (1983), pp. 115-138.

Putnam, Hilary: 1979b, Mathematics, Matter and Method: Philosophical Papers, vol. 1, $2^{\text {nd }}$ ed., Cambridge University Press, Cambridge.

Putnam, Hilary: 1983, Realism and Reason: Philosophical Papers, vol. 3, Cambridge University Press, Cambridge.

Putnam, Hilary: 1994a, 'Rethinking Mathematical Necessity', in Putnam (1994b), pp. 245-263.

Putnam, Hilary: 1994b, Words and Life, ed. James Conant, Harvard University Press, Cambridge, MA, pp. 245-263.

Quine, Willard V.: 1951, 'Two Dogmas of Empiricism', reprinted with revisions in W. V. Quine (1980), From a Logical Point of View, $2^{\text {nd }}$ ed., Harvard University Press, Cambridge, MA, pp. 20-46.

Reichenbach, Hans: [1920]/ 1965, The Theory of Relativity and A Priori Knowledge, trans. Maria Reichenbach, University of California Press, Berkeley, CA.

Richardson, Alan W.: 2002, 'Narrating the History of Reason Itself: Friedman, Kuhn, and a Constitutive A Priori for the Twenty-First Century', Perspectives on Science 10, 
253-274.

Salmon, Wesley C.: 1984, Scientific Explanation and the Causal Structure of the World. Princeton University Press, Princeton, NJ.

Stump, David J.: 2003, 'Defending Conventions as Functionally A Priori Knowledge', Philosophy of Science 70, 1149-1160.

Wimsatt, William C.: 1987, 'Generative Entrenchment, Scientific Change, and the Analytic-Synthetic Distinction: A Developmental Model of Scientific Evolution', invited address at the Western (now Central) Division of the APA meetings, unpublished ms., $18 \mathrm{pp}$.

Wimsatt, William C.: 2001, 'Generative Entrenchment and the Developmental Systems Approach to Evolutionary Processes', in Susan Oyama, Russell Gray, \& Paul Griffiths (eds.), Cycles of Contingency: Developmental Systems and Evolution, MIT Press, Cambridge, MA, pp. 219-238.

Wimsatt, William C.: forthcoming, 'Epilogue: Robustness and Entrenchment-How the Contingent becomes Necessary', in William C. Wimsatt, Re-Engineering Philosophy for Limited Beings, Harvard University Press, Cambridge, MA. 